\title{
Iglesia y Memoria: la Biblioteca y el Archivo Secreto Vaticano*
}

\author{
Monseñor Jean-Louis Bruguès, OP \\ ARCHIVERO Y BIBLIOTECARIO DE LA SANTA IGLESIA ROMANA
}

1. "Hagan esto en memoria mía". Pocas frases, pocas palabras en el Evangelio nos ofrecen tanta consistencia como esta. Repetida en dos ocasiones, ambas recuerdan la institución de la Eucaristía (Lc 22, 19 y 1 Co 11, 24-25), nosotros la repetimos también cuando celebramos la Santa Misa. Como en eco, San Pablo responde: "Acuérdate de Jesucristo" (2 Tm 2, 8). Estas palabras nos dejan considerar cuán estrecha es la relación entre la Iglesia y la memoria. La conmemoración es el núcleo de la misión de la Iglesia. En su exhortación Evangelii gaudium, el papa Francisco explica que "La memoria es una dimensión de nuestra fe que podríamos llamar «deuteronómica», en analogía con la memoria de Israel. Jesús nos deja la Eucaristía como memoria cotidiana de la Iglesia” (\$ 13). En la siguiente conferencia, deseo dedicarme precisamente a comprender y a precisar esta relación.

2. El Papa habla de una "memoria deuteronómica”: ¿Qué quiere decir eso? En el Antiguo Testamento, cuando Dios se dirige a su pueblo para revelarle lo que va a hacer por él y, más tarde, lo que esperará de él, empieza por recordarle lo que ya antes hizo por él. Antes de darle su Ley en el Decálogo, se presenta de la siguiente manera: "Yo soy Yahvé, tu Dios que te ha sacado de la tierra de Egipto, de la casa de la servidumbre" (Dt 5, 6). Vemos cómo el acto de memoria cumple una doble función. Por una parte, permite acceder a la identidad. En este caso, se trata de la identidad de Dios aunque la

Este texto corresponde a la conferencia dictada por monseñor Jean-Louis Bruguès, OP, el día 27 de mayo de 2014 en la Biblioteca Nacional de Chile, en el contexto de su visita a la Pontificia Universidad Católica de Chile. 
constatación vale igualmente para los humanos: cuando una persona tiene dudas sobre mi identidad, solicito su memoria y le recuerdo hechos pasados, o las circunstancias de un encuentro precedente que le ayudarán a situarme. De hecho, hay en francés una hermosa expresión para apartar la duda: "Vous me remettez?" la cual quiere decir literalmente, " $¿$ me ubica/ me coloca usted?", le preguntamos a la persona que parece no recordarnos. Por otra parte, el acto de la memoria establece la confianza: si el pueblo accede a las exigencias -en este caso, obedecer la Ley- y las promesas de Dios, es porque Él los ha liberado de la servidumbre en Egipto. Ahora bien, esta observación vale también para la vida social: si me fío hoy del comportamiento que tiene conmigo una persona, es porque me acuerdo del bien que esta me hizo en el pasado. Identidad y confianza: recordemos estos dos términos, pues serán nuestro hilo conductor.

3. La cohesión de un grupo social, sea este político o religioso, y más aún, el porvenir de un grupo social, dependen en gran parte de la relación que mantienen con la memoria de su fundación. Por ejemplo, el apego que se siente por Europa no será el mismo, según si uno se refiere a los "padres fundadores", Robert Schuman y Alcide de Gasperi, y al espíritu con el cual dispusieron las fundaciones, o bien según si uno considera que Europa no necesita interrogarse sobre sus orígenes, pues se trata más bien de una idea que ha de ser reactualizada constantemente. Esa es una cuestión esencial sobre la identidad. De hecho, he notado que en las ciudades latinoamericanas, son numerosas las avenidas que llevan el nombre del fundador de la nación, aquí O’Higgins, allá Bolívar...

4. Para el cristianismo, Jesús de Nazaret, verdadero Dios y hombre verdadero, es su fundador. Es el título que había escogido el teólogo Joseph Ratzinger, siendo Papa, Benedicto XVI, para su trilogía publicada entre el 2007 y el 2012. Hace unos meses, la Fundación Joseph Ratzinger/Benedicto XVI organizó, en Roma, un simposio para tratar este tema: ¿Cómo puede uno conseguir la imagen más justa y auténtica del fundador? ¿Nos permiten los evangelistas descubrir de manera fiable el hombre histórico, Jesús de Nazaret? De una manera aún más relevante que para otras religiones que no tienen precisamente un fundador histórico preciso como el hinduismo, al cristianismo le es vital demostrar su fidelidad a la persona misma de Cristo, a sus promesas y a todo aquello que ha dicho y hecho o 
-como dirían los teólogos medievales- a las acta et passa de Cristo .

El CRISTIANISMO PRACTICA CUATRO FORMAS DE ACTOS DE MEMORIA

5. Primero está lo que se podría llamar la memoria de los lugares. El creyente siente la necesidad de reencontrarse en los lugares donde el Cristo ha vivido, de respirar el mismo aire que él, de ver la misma luz, de recorrer los mismos itinerarios, de tocar las piedras, incluso las construcciones que sin lugar a duda, lo vieron pasar... Es admirable la precisión de los evangelios, mencionando aquí un pueblo, o un barrio de Jerusalén, más allá una montaña o las orillas de un río donde Jesús se fue a predicar, a cumplir milagros o a rezar. En su libro, $\mathrm{La}$ Galilée, el escritor francés Pierre Loti, que vivió en Valparaíso, canta la dulzura de los paisajes que conoció Cristo; escuchaba el silbido de lo cabreros cuyo sonido debía resonar igual que a lo largo de todos los siglos pasados. Hallamos semejante expresión vehemente de la aspiración del creyente en la estrategia amorosa. ¿Cuando el ser amado nos ha dejado, no sentimos acaso la necesidad de volver a encontrar los lugares y las cosas que nos hablan de él, a pesar de la ausencia?

Bien sé que el "políticamente correcto" nos quiere forzar a ver en las cruzadas el famoso fenómeno del choque de las civilizaciones, o también una prefiguración de las extensas empresas de colonización que marcaron la historia occidental de los siglos XVI y XIX. No obstante, la realidad es más sencilla y, antes que nada, religiosa, por lo cual tan solo puede pasar inadvertida para las mentalidades secularizadas: los cristianos deseaban conservar un acceso libre a los sitios donde vivió Jesús de Nazaret, con el fin de entenderlo y venerarlo mejor, en definitiva, "visitarlo".

6. Por extensión, la memoria cristiana - precisando que aquí se trata de la memoria católica y de la memoria ortodoxa, ya que no corresponde con la memoria protestante- busca un contacto con los que conocieron de cerca al Cristo. A esta segunda forma, llamémosla memoria de la proximidad. Sea porque fueron sus contemporáneos (la Virgen María y sus discípulos) o, porque su santidad los hacía imágenes particularmente conmovedoras de la santidad del Cristo, pero el hecho de aproximarse a los que se le acercaron, es también reunirse y encaminarse hacia el Cristo mismo.

De esta manera se explica el fenómeno de los peregrinajes que convierten el cristianismo, una religión histórica, en una religión 
propiamente carnal en la cual el creyente siente la necesidad de tocar para ser él también, tocado. Es cierto que el peregrinaje en sí, no es específico de nuestra religión: bastaría con nombrar La Meca o Benarés; en cuyos casos uno viene a cumplir con los preceptos o a pedir un favor, como por ejemplo, una curación. Estas motivaciones no son desconocidas de la práctica cristiana, no obstante y ante todo, hay una voluntad de ir al encuentro del fundador mediante los que adecuaron sus vidas a la de Cristo. Además de estos viajes por los lugares de Palestina que acabamos de mencionar, se ha de nombrar los grandes peregrinajes marianos como Lourdes o Guadalupe y también, los que llevan a las tumbas de los apóstoles, a Roma, o a Santiago de Compostela.

7. El tercer acto de memoria es aún más original. La Iglesia es llamada el Cuerpo de Cristo. Al recordar los hechos y las palabras de su fundador, no se apega sencillamente a un acatamiento literario o a una coherencia histórica como se podría hacer con cualquier personaje del pasado, la Iglesia enseña y difunde sus mensajes y sus actos de cada día. La sacramentalidad constituye su esencia misma. La Iglesia se esfuerza para que los hombres de todas las civilizaciones y de todos los tiempos, sientan la presencia activa de Cristo. En ello consiste su misión esencial. Un sacramento transmite la vida misma del Cristo resucitado, y hace del que lo recibe un participante a su propia esencia; es una fuente de gracia. Por lo tanto, uno puede hablar de memoria sacramental.

8. El cuidado que muestra el cristianismo por conservar y guardar los escritos que tratan sobre Cristo, su paso entre los hombres y sobre la fundación de su Iglesia, demuestra una preocupación del recuerdo. Esto sería lo que podríamos llamar, la memoria de los escritos. Esta cuarta manera de hacer memoria nos retendrá más prolongadamente, puesto que corresponde al corazón de mi discurso. Ya en los primeros tiempos de la Iglesia de Roma, los papas tomaron la costumbre de conservar en sus scrinium (archivos) personales las gesta martyrum, los códigos litúrgicos, las memorias de las consagraciones episcopales, las donaciones a la Iglesia. La exigencia de conservar estos documentos nació de la necesidad de transmitir el recuerdo del fundador y la memoria de la acción de la Iglesia naciente. A partir del siglo IV, después de las persecuciones, los archivos de la Iglesia de Roma se enriquecen con documentos, códices, libros provinciales, fórmulas de juramento, testimonios de consagración de 
iglesias, papiros sobre la correspondencia dirigida a los pontífices por los emperadores de Oriente, antes, y de Occidente después, y otros escritos pastorales y administrativos... De esta manera emergió uno de los fondos más ricos de la humanidad.

Cuando el papa Benedicto XVI me nombró en el puesto que sigo ocupando, me confió que él habría soñado con ocupar mi sitio, si no hubiese sido elegido para ocupar el trono de Pedro. Agregó: "Confío a usted los tesoros de la Iglesia”. Este término nos puede extrañar: ante todo, los verdaderos tesoros de la Iglesia son los santos, los sacramentos o los pobres. Sin embargo, hay que comprender por qué, a pesar de todo, aquello está justificado.

9. Estos "tesoros" están repartidos entre dos instituciones, que se avecinan geográficamente, dado que ambas ocupan el Cortile del Belvedere, pero son estrictamente independientes la una de la otra. La Biblioteca Apostólica Vaticana (BAV) y el Archivo Secreto del Vaticano (ASV), tan solo poseen un enlace común, y es lo que encabeza a las dos. La BAV fue fundada poco antes de 1450 , por el papa Nicolás $V$ quien había intervenido antes en la creación de la primera biblioteca moderna del conven- to dominicano de San Marcos de Florencia (donde se hallan los magníficos frescos de Fra Angélico). El Papa ordenó la adquisición de libros en todos los mercados de Oriente y Occidente; envió a sus hombres de confianza a los rincones más remotos con el fin de recuperar las obras más representativas del genio humano. Las adquisiciones se mantuvieron a un ritmo variable pero hasta hoy en día, de manera ininterrumpida.

10. Si tuviese que calificar con una palabra la $\mathrm{BAV}$, diría que es una biblioteca humanista. Es humanista por la voluntad misma de su fundador, pues aspira a recopilar lo mejor de la cultura humana. Por lo que no se trata de una biblioteca eclesiástica, como las que se pueden encontrar en los seminarios o en las facultades de teología, aunque abunden las obras de teología, de filosofía y de derecho canónico. Tampoco es una biblioteca nacional en la cual se depositen por decreto de ley todas las obras impresas en el país. Sus fondos más extensos son los de la Biblia y los manuscritos antiguos, los de ciencia, de matemáticas y de astronomía en particular, de historia del mundo y de arte (sobre todo de música y dibujo), sin olvidar una de las más grandes colecciones de medallas que existan. Por ejemplo, nuestra BAV se en- 
orgullece de tener en su posesión, el famoso Codex Vaticanus siendo este el más antiguo manuscrito completo de la Biblia en griego (lo tiene desde el final del siglo XV); el papiro Bodmer XIV-XV (Papiro "Mater Verbi"), "Dono della famiglia Hanna e della Solidarity Association", adquirido recientemente y que conserva el final del Evangelio de Lucas y el principio del Evangelio de San Juan (entre 180 y 220).

De paso, permítanme hacerles una observación: hoy en día se acostumbra muy a menudo designar al cristianismo, de la misma manera que al islam, como una «religión del libro», lo cual es erróneo. Para nosotros, el libro no representa más que un soporte material que nos abre las puertas del corazón y del espíritu a la obra del Espíritu Santo. La letra mata, el espíritu da vida (2 Co 3, 6).

La BAV es también una biblioteca humanista puesto que desde su creación, acoge a los investigadores del mundo entero sin objeción o consideración alguna sobre sus orígenes o convicciones personales. De hecho, son varios millares los que frecuentan nuestras salas de consulta, tan solo les pedimos que posean un doctorado y que sean recomendados por una autoridad académica.
11. El escritor latino Terencio decía que "Nada de lo humano me es ajeno". Esto es más verídico aun para la Iglesia: todo lo que es humano le recuerda a Dios, pues la humanidad ha sido creada a la imagen de Dios. Por ello, podemos hablar de una memoria del humanismo: ella aspira a resguardar las huellas del saber humano en todos sus dominios, sean estas en ciencia o en una de las múltiples formas del arte. En el "Salone sixtino", las representaciones de las grandes bibliotecas de la humanidad están ubicadas frente a los grandes concilios ecuménicos, ilustrando de esta manera el diálogo necesario entre la fe y la razón.

12. Tres bibliotecas se disputan la preeminencia en la custodia de los fondos más antiguos: Londres, París y la Vaticana (yo diría que el nuestro es un poco inferior en número, pero incontestablemente más rico). Con casi 10.000 incunables llegamos en cuarta posición. Les preciso dos cifras para aclarar las ideas: 160 personas trabajan ahí -lo cual es ridículamente bajo, si lo comparamos con los millares de empleados en las grandes bibliotecas del mundo-; son casi exclusivamente laicos, entre los cuales las mujeres son mayoría; y la biblioteca cuenta con unos 54 $\mathrm{km}$ de estanterías. Año tras año, los espacios se hacen cada vez más 
escasos: hace menos de un mes estuvimos -con el nuevo secretario de Estado- considerando diversas hipótesis no para construir sino para excavar, ya que esa es la única posibilidad de agrandar, siendo el Vaticano un Estado tan pequeño.

13. Conservar y poner a disposición: esta es la preocupación de cualquier biblioteca. El proyecto de digitalización, que iniciamos hace más de diez años en nuestro caso, será el centro de todos los esfuerzos de la BAV en los próximos años. Se concentrará en los manuscritos y los escritos antiguos, puesto que los otros libros impresos están a disposición en otras bibliotecas. Las sumas que exige semejante inversión son considerables, muy superiores a las capacidades financieras de la Santa Sede. Por ello, asesorados por algunas universidades católicas americanas que tienen experiencia, acabamos de lanzar una ambiciosa política de fund raising. Así es como en el mes de marzo pasado llegué a un acuerdo de unos 19 millones de euros con una prestigiosa empresa japonesa, para programar la digitalización de unos 3.000 manuscritos en los próximos 4 años.

14. “¿Me podría explicar usted cómo tomaron la decisión de ayudarnos de esta manera?", le había preguntado yo al director general japonés sabiendo que ni un solo cristiano trabajaba en su empresa. La respuesta que recibí merece ser compartida: "Porque queremos servir a la humanidad y, a nuestro parecer, representáis un humanismo excepcional". El humanismo de nuestra institución promueve en paralelo una diplomacia que ubica a la BAV en el corazón de la política cultural de la Iglesia católica. Varias bibliotecas nacionales de América Latina nos han pedido que las ayudemos. Y mantenemos una buena relación con países musulmanes, tales como Irán, Azerbaidjan y Qatar; pero también con la China comunista: financiada por el gobierno comunista, la numerizacion de nuestros fondos chinos, abrirá nuevas posibilidades tales como, exposiciones comunes entre China y el Vaticano, en Beijing y en otras grandes ciudades, a pesar de que estos dos Estados no tengan ninguna relación diplomática...

15. La denominación de Archivos Secretos habrá hecho fantasear a más de uno. ¿Acaso me es necesario precisar cuán alejada está nuestra institución de las fantasías retorcidas de Dan Brown? Se los llama Archivos Secretos, no porque sus contenidos secretos amenacen el equilibrio de la Iglesia y el porvenir de la humanidad, sino porque están reservados al uso exclusivo 
del Papa: secretum significa a la disposición de. En cambio, con sus 87 $\mathrm{km}$ de estantería y por consiguiente, sus millones de documentos de orígenes bien antiguos, ciertamente los Archivos son considerados como los más ricos del mundo.

16. Los Archivos son al mismo tiempo, más antiguos y más recientes que la BAV. En la medida en que los primeros papas se preocuparon -como ya lo mencionamos- de colectar y conservar todos los documentos relativos a la vida de la Iglesia, los Archivos son más antiguos. Estos archivos se desplazaban con la corte pontificia o eran almacenados en la Residencia de Letrán o en el castillo de Sant'Angelo: con lo cual solo una ínfima parte de este inestimable patrimonio llegó a nuestros días. Las causas de las pérdidas eran múltiples: fragilidad del papiro, pérdidas en el transcurso de los desplazamientos, de las guerras o de los saqueos... Habrá que esperar al papa Pablo V (1605-1621) para que por fin se tome la decisión de constituir los únicos archivos centrales de la Iglesia. Su nacimiento llega pues, un siglo y medio después de la BAV.

17. Otras etapas cargadas de consecuencias han de ser mencionadas, como las cesiones forzadas a París, en 1810, bajo la orden de
Napoleón, al igual que su devolución y las pérdidas que uno puede imaginar en el camino de regreso. Más tarde, en 1881, la decisión tomada por León XIII de abrir la libre consulta a los investigadores, hizo de los Archivos uno de los centros de investigación histórica más importantes del mundo. También, la creación de la escuela vaticana de paleografía y de diplomacia; al igual que la grandiosa construcción de un edificio subterráneo en el subsuelo del Patio de la Pigna en 1980 (siendo esta una obra de alta ingeniería de dos plantas realizadas en hormigón armado, capaz de resistir a una explosión atómica). Año tras año, llegan cada vez más aportaciones nuevas, a tal punto que hoy en día, los 59 empleados no consiguen incorporarlo todo al registro. Yo estoy convencido de que tenemos tesoros - jotra vez más con esa palabra!- en nuestro establecimiento que aún no han sido registrados, no porque nuestra intención sea de esconder algún escándalo, pero simplemente por falta de medios. Con ello se confirma, una vez más, la pobreza de la Iglesia.

18. Sería largo y tedioso comunicaros una lista de los documentos más prestigiosos. Me bastará con mencionaros el diploma de Otón I, escrito con oro sobre un pergamino púrpura (862); la carta 
del Gran Khan de los Mongoles al Papa de 1246; las bulas de excomunión de Lutero; la carta del Parlamento inglés, firmada por todos sus miembros, que pide al Papa la anulación del matrimonio de Enrique VIII; la carta en seda de la emperatriz Wang-Elena de China (1650); o también, los documentos pontificios relacionados con dogmas y concilios. Puesto que los Archivos están reservados únicamente al Sumo Pontífice, solo él puede tomar la decisión de abrir al público tal o tal fracción. Por lo tanto, estamos a la espera de su permiso para abrir los archivos que conciernen el pontificado de Pío XII.

19. La importancia de los archivos y de una biblioteca, no se mide solamente por el número de obras conservadas o por la antigüedad de los documentos. Siendo espacios de memoria, se convierten necesariamente en símbolos mayores de la identidad del grupo correspondiente. Cuando Hitler quiso trastornar y herir el alma polaca, mandó quemar la biblioteca nacional. Napoleón envió a París gran parte de la biblioteca del Vaticano, antes de que el Congreso de Viena ordenase su repatriación. Evidentemente, las bibliotecas y los archivos se han convertido en símbolos de la identidad social y por ello mismo quedan expuestos a los conflictos ideológicos. Estos conflictos no dejan de producir divisiones dentro de la misma Iglesia. Se reprocha usualmente a las bibliotecas su alto coste. De manera bastante repetida, un cierto romanticismo de la pobreza ha empujado a la Iglesia a deshacerse de estos "signos externos de riqueza y de poder”. ¡Esto conllevó a que en mayo de 1968 unos dominicos franceses propusieran incluso abandonar la biblioteca de Saulchoir que era la segunda biblioteca privada de Francia!

Son numerosas las manifestaciones antiintelectuales o antihumanistas que han sacudido la historia de la Iglesia, proponiendo simplificar y arrinconar la innecesaria carga de la cultura o contentarse sencillamente con la cercanía inmediata de la Biblia. Pareciera como si la cultura humana tuviese que ser disociada de la fe o transformada en un obstáculo para la fe. ¿YY qué sentido tiene saber todo eso, me preguntaba un día una persona a la que yo intentaba abrir a las riquezas de la cultura cristiana? Solo basta con tener fe y la fe es para los simples.

20. La Iglesia es una de las instituciones existentes más antiguas de la humanidad, más que los Estados, más aún que las universidades. Presente desde el comienzo 
en Israel (Lumen Gentium, 9), la Iglesia atravesó civilizaciones que desaparecieron pero de las que conservó gran parte del patrimonio moral, del esfuerzo de aquellos hombres de buena voluntad que quisieron llevar una vida feliz en una ciudad más justa. Sin duda conviene elogiar el silencioso trabajo de los monjes y de los copistas, quienes al ponerse al servicio de Dios, se dedicaron a conservar y transmitir la sabiduría de los antiguos. En consecuencia, aunque uno no lo quiera, la memoria de la Iglesia se convirtió en la memoria de una gran parte de la humanidad. Y por ende, la memoria cristiana no pertenece a la Iglesia solamente, y ella no podría comportarse como si fuese su propietaria, decidiendo con arbitrariedad de guardar esto y de rechazar lo otro. No es su propietaria y no lo puede ser. Todo lo contrario: le incumbe velar cuidadosamente por este yacimiento, que sin ser el de la $\mathrm{fe}$, no es menos valioso o preciado.

21. Por este motivo, le atañe a la Iglesia desempeñar un papel decisivo en el progreso moral de la humanidad. De hecho, el progreso exige e implica una conciencia viva e íntegra del patrimonio. Incluso en las sociedades secularizadas y, en cierta manera sobre todo en ellas, puesto que se muestran tan propensas a borrar el pasado.
La Iglesia es la guardiana de la memoria. Por sobre la diversidad de sus opiniones, a pesar de que no compartan la fe cristiana y sobre todo aunque se opongan a ella, los contemporáneos cuestionan y sondean su propia memoria en la Iglesia. La mayoría no espera más, como se hizo en los tiempos de cristiandad, prescripciones o normas, pero sí reclaman y necesitan un enunciado de valores fundamentales que den testimonio, a través de las múltiples culturas, del esfuerzo común de los hombres hacia lo "bello y lo bueno".

22. Sería un gran error si a esta vigilancia, la comparásemos con la de un guardia de museo. Ciertamente la Iglesia conserva, pero para salvar. Su custodia es la de un profeta. En 1965, en su primera aparición pública en la tribuna de las Naciones Unidas, el papa Pablo VI se presentó con estas palabras: "Mi nombre es Pedro; soy un experto en humanidad". El papel de la Iglesia consiste en custodiar y animar. Con la asistencia del Espíritu Santo, su mirada llega lejos: aclara y clarifica a los contemporáneos sobre lo que podríamos llamar, "la transcendencia de los desafíos".

Esta misión profética no deja de exponer a la Iglesia a un enfrentamiento con una cierta modernidad, la que no considera que la 
Historia aporte respuesta alguna a las cuestiones del tiempo presente. En realidad, esta modernidad no carece de contradicciones. La modernidad técnica se consagra escrupulosamente a la conservación de los datos, lo cual en cierta manera se refiere a la memoria pues sabe que "cada generación no puede reinventar la rueda”. En cambio, para los temas de antropología, esta modernidad considera que los antiguos nada tienen que enseñarle. A tiempos nuevos, soluciones nuevas. De hecho, es notorio cómo la enseñanza en la escuela asigna un lugar cada vez más reducido a las ciencias de la memoria, a favor de las materias científicas.

23. Finalmente, cabe mencionar esta evidencia que se impone a nosotros: cuando uno pierde su memoria, pierde igualmente su identidad y es incapaz de dirigirse o comportarse. Un amnésico no tiene futuro. La misma ob- servación se aplica a las personas que padecen una patología como el Alzheimer, y se les borra la memoria. Eso vale también para los grupos sociales y las naciones. Por esta razón se instituyen y se programan las celebraciones de aniversarios y de fiestas memoriales. Pero es inevitable dudar de su eficacia, cuando uno observa que las generaciones más jóvenes no son iniciadas a las riquezas de un pasado común, y cuando las generaciones precedentes no se preocupan de transmitir un patrimonio que no les pertenece. En ese sentido, la crisis de 1968 puede ser considerada como una crisis de la memoria: por primera vez quizás en la Historia, una generación decidió hacer del pasado tabla rasa. Consciente y voluntariamente, ella tomó la decisión de no trasmitir. Ahora bien, "Chi non ricorda, non vive”, aseguraba el antropólogo italiano Giorgio Pasquale. 
